\title{
Creep and drying shrinkage of a blended slag and low calcium fly ash geopolymer Concrete
}

\author{
A. Castel · S. J. Foster • T. Ng • J. G. Sanjayan • \\ R. I. Gilbert
}

Received: 30 April 2014/ Accepted: 18 March 2015/Published online: 24 March 2015

(C) RILEM 2015

\begin{abstract}
The main purpose of this research is to study the time dependent behaviour of a geopolymer concrete. The geopolymer binder is composed of $85.2 \%$ of low calcium fly ash and only $14.8 \%$ of ground granulated blast furnace slag. Both drying shrinkage and creep are studied. In addition, different curing conditions at elevated temperature were used. All experimental results were compared to predictions made using the Eurocode 2. The curing regime plays an important role in the magnitude and development of both creep and drying shrinkage of class F fly ash based geopolymer concrete. A minimum of 3 days at $40{ }^{\circ} \mathrm{C}$ or 1 day at $80{ }^{\circ} \mathrm{C}$ is required to obtain final drying shrinkage strains similar to or less than those adopted by Eurocode 2 for ordinary Portland cement (OPC) concrete. Creep strains were similar or less than those predicted by Eurocode 2 for OPC concrete when the geopolymer concrete was cured for 3 days at $40{ }^{\circ} \mathrm{C}$. After 7 days at $80{ }^{\circ} \mathrm{C}$, creep strains became negligible.
\end{abstract}

A. Castel $(\bowtie) \cdot$ S. J. Foster · T. Ng · R. I. Gilbert Centre for Infrastructure Engineering and Safety, School of Civil and Environmental Engineering, The University of New South Wales, Sydney, NSW, Australia e-mail: a.castel@unsw.edu.au

\section{J. G. Sanjayan}

Centre for Sustainable Infrastructure, Swinburne University of Technology, Hawthorn, VIC, Australia
Keywords Sustainability - Geopolymer concrete . Fly ash · Creep $\cdot$ Shrinkage

\section{Introduction}

Reinforced concrete is the most common construction material. Manufacturing of ordinary Portland cement (OPC) involves mining, crushing and grinding limestone and shale, which are then burned in a rotary kiln to convert the limestone into lime via a process known as calcination, and finally grinding the resulting cement clinker with gypsum. The production of Portland cement is very energy intensive and releases large amounts of greenhouse gases (GHG), mainly carbon dioxide $\left(\mathrm{CO}_{2}\right)$, and contributes to about $7 \%$ of global anthropogenic $\mathrm{CO}_{2}$ emissions and accounts for $4 \%$ of man-made global warming [1,2]. Every tonne of Portland cement replaced with supplementary cementitious materials such as fly ash or slag is estimated to avoid the emission of about one tonne of $\mathrm{CO}_{2}$ to the atmosphere $[3,4]$. The contribution of OPC manufacture to carbon emissions is second only to fossil fuels [5].

Over the last two decades, geopolymer concretes have emerged as novel engineering materials with the potential to become a substantial element in an environmentally sustainable construction and building products industry [6-8]. Geopolymer concrete is the result of the reaction of materials containing 
aluminosilicate with alkalis to produce an inorganic polymer binder. In many regions of the world similar to Australia, industrial waste materials such as fly ash and blast furnace slag are commonly used as the source of aluminosilicate for the manufacture of geopolymer concrete due to the low cost and wide availability of these materials. There is no Portland cement clinker in geopolymer concrete. Geopolymer concrete (GC) was first investigated in the 1940s attracting significant academic research. It was even used in some construction projects in the USSR in the 1960s [9] demonstrating the feasibility of more widespread use. In the 1970s, Prof Davidovits pioneered the development of geopolymer in Western Europe [10]. The considerable sustainability benefits of using a binder system composed almost entirely of recycled materials has led to considerable research on GCs in recent years [11-14]. Geopolymer binder can provide reduction of embodied $\mathrm{CO}_{2}$ of up to $80 \%$ compared to OPC with efficient use of other industrial by-products [6].

Geopolymer concretes exhibit many of the characteristics of traditional concretes, despite their vastly different chemical constituents and reactions $[15,16]$ The mixing process, the workability of freshly mixed geopolymers, the mechanical characteristics of the hardened material appear to be similar to those for traditional OPC concretes. However, only a few attempts to assess the drying shrinkage and creep characteristics of fly ash based geopolymer concrete are available in the literature. A study by Wallah and Rangan [17, 18] at Curtain University of Technology in Australia, showed that heat-cured fly ash-based geopolymer concrete undergoes low creep, about $50 \%$ of the creep usually observed for OPC based concrete as predicted by the Australian Standard AS3600-2009. Tests specimens were cured at $60{ }^{\circ} \mathrm{C}$ for $24 \mathrm{~h}$. The creep tests were started on the seventh day after casting and the sustained load applied was $40 \%$ of the compressive strength as determined on the day when the creep testing started. Drying shrinkage was also studied using two curing procedures: (i) ambient temperature for 3 days; and (ii) heat cured at $60{ }^{\circ} \mathrm{C}$ for $24 \mathrm{~h}$ and then 2 days in water at $23{ }^{\circ} \mathrm{C}$. All shrinkage tests were started after 3 days. The drying shrinkage strain of ambient-cured specimens was in the order of 1500 micro-strains after 3 months, which is about two to three times higher than that expected for an equivalent OPC based concrete [19]. Heat cured specimens however performed very well, with only
100 micro-strains after 3 months. More recently, Sagoe-Crentsil [20] carried out similar tests using a similar low calcium fly ash geopolymer concrete. Tests specimens were cured at $60{ }^{\circ} \mathrm{C}$ for $6 \mathrm{~h}$ only and then stored in a fog room at $23{ }^{\circ} \mathrm{C}$. Creep and shrinkage tests were started after 28 and 7 days respectively. Creep results were similar to those obtained by [17]. The strain due to drying shrinkage of ambient-cured specimens was in the order of 250 micro-strains after three months, which is higher than the ones obtained by Wallah and Rangan [18]. This is likely because of the shorter heat curing duration but, according to [19], it is still about half the value predicted for an equivalent OPC based concrete.

In this paper, further investigations are carried out in order to assess the influence of the age of the geopolymer concrete when the shrinkage test starts. Shrinkage tests were started 24 h, 3 or 8 days after casting. It is important to assess the drying shrinkage as early as possible because it is responsible for early age cracking that occurs when the concrete does not have much strength. According to ASTM C157 [21] shrinkage tests must start $24 \mathrm{~h}$ after casting. Moreover, alternative curing temperatures $\left(40\right.$ and $80^{\circ} \mathrm{C}$ ) and duration are explored. Creep tests were started after 8 days considering two alternative heat curing regimes: 40 and $80{ }^{\circ} \mathrm{C}$. This work will contribute to increasing the amount of experimental data available in the literature regarding the time-dependent behaviour of low calcium fly ash geopolymer concrete.

\section{Experimental program}

\subsection{Geopolymer binder}

A testing programme [8] was undertaken using fly ash (FA) from Eraring Power Station in New South Wales, Australia, Kaolite high-performance ash (HPA) from Callide Power Station in Queensland, Australia, and ground granulated blast furnace slag (GGBFS). The chemical compositions of the FA, HPA and GGBFS are presented in Table 1. Both fly ashes are low calcium class F fly ash. The grading curves for the FA, HPA and GGBFS are shown in Fig. 1. The aim of the experimental programme was to investigate the effect of blending different types of aluminosilicate materials. Indeed, in Australia, suppliers often receive fly ash 
Table 1 Fly ash and GGBFS chemical compositions

\begin{tabular}{lccc}
\hline Element & FA & HPA & GGBFS \\
\hline $\mathrm{SiO}_{2}$ & 66.56 & 45.14 & 34.09 \\
$\mathrm{Al}_{2} \mathrm{O}_{3}$ & 22.47 & 33.32 & 13.81 \\
$\mathrm{Fe}_{2} \mathrm{O}_{3}$ & 3.54 & 11.99 & 0.53 \\
$\mathrm{CaO}$ & 1.64 & 4.13 & 41.75 \\
$\mathrm{~K} 2 \mathrm{O}$ & 1.75 & 0.13 & 0.28 \\
$\mathrm{Na} 2 \mathrm{O}$ & 0.58 & 0.07 & 0.37 \\
$\mathrm{MgO}$ & 0.65 & 1.37 & 5.55 \\
$\mathrm{Mn}_{3} \mathrm{O}_{4}$ & 0.06 & 0.23 & 0.41 \\
$\mathrm{P}_{2} \mathrm{O}_{5}$ & 0.11 & 0.56 & 0.01 \\
$\mathrm{TiO}_{2}$ & 0.88 & 2.19 & 1.38 \\
$\mathrm{SO}_{3}$ & 0.1 & 0.48 & 2.61 \\
$\mathrm{LOI} \%)$ & 1.66 & 0.41 & 0.9 \\
\hline
\end{tabular}

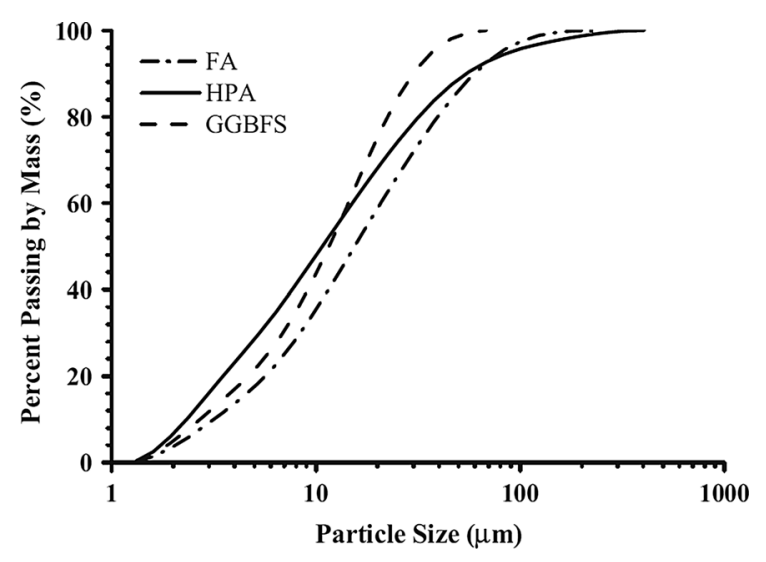

Fig. 1 Grading curves for the FA, HPA and GGBFS

from two sources and they blend both to achieve consistent quality of their supply. Fifteen series of geopolymer mortar with different mix proportion were tested after 28 days [8].

The alkaline activator used is a mixture of sodium hydroxide $(\mathrm{NaOH})$ solution and sodium silicate $\left(\mathrm{Na}_{2-}\right.$ $\mathrm{SiO}_{3}$ ) solution. The ratio of sodium silicate to sodium hydroxide solution used was 2.5:1 (by mass). The sodium hydroxide solution used was prepared by dissolving the technical grade $\mathrm{NaOH}$ pellets in water. The sodium hydroxide white pellets with a purity of at least $98 \%$ were supplied by Ajax Finechem under the commercial brand of UNIVAR A-302. These pellets have a molecular weight of 40 and a specific gravity of 2.1. The concentration of sodium hydroxide solution used is 12 molar (M) consisted of 480 grams ( $\mathrm{g}$ ) of $\mathrm{NaOH}$ pellets per litre of $\mathrm{NaOH}$ solution or $361 \mathrm{~g}$ of
$\mathrm{NaOH}$ pellets per $\mathrm{kg}$ of $\mathrm{NaOH}$ solution. The Sydney tap water was used in this study as the solvent to produce the $\mathrm{NaOH}$ solution. The above mentioned concentration $(12 \mathrm{M})$ of sodium hydroxide solution has been selected according to the preliminary works conducted by Palomo et al. [22]. In their investigation on different concentrations (8-14 M) of $\mathrm{NaOH}$ solution, it has been observed that the mechanical performance of GPC increases by increase in the $\mathrm{NaOH}$ concentration up to $12 \mathrm{M}$ and further increase in $\mathrm{NaOH}$ concentration has a negative effect on the strength.

The sodium silicate solution used, which was manufactured by PQ Australia under the commercial name of Vistrol D-A53 or grade D, has a chemical composition of $\mathrm{Na}_{2} \mathrm{O}=14.7 \%, \mathrm{SiO}_{2}=29.4 \%$, and $\mathrm{H}_{2} \mathrm{O}=55.9 \%$ (by mass) with a modulus ratio $\left(M_{\mathrm{s}}\right)$ of $2\left(M_{\mathrm{s}}=\mathrm{SiO}_{2} / \mathrm{Na}_{2} \mathrm{O}=2\right)$. The $\mathrm{Na}_{2} \mathrm{SiO}_{3}$ solution used, also known as waterglass, is a thick adhesive liquid with a viscosity of $400 \mathrm{cps}$ at $20{ }^{\circ} \mathrm{C}$, has a specific gravity of 1.53 and a $\mathrm{pH}$ of 12.9 (values provided by supplier, PQ Australia). The activator solution was prepared and mixed together $24 \mathrm{~h}$ prior to usage. The $\mathrm{pH}$ of the activator solution (mixture of sodium silicate and $12 \mathrm{M}$ sodium hydroxide with the ratio of 2.5:1) has been measured using an appropriately calibrated $\mathrm{pH}$-meter and was equal to 14 .

One day after casting, the specimens were demoulded and cured in a $90{ }^{\circ} \mathrm{C}$ water bath for a further 7 days. Using this hot curing process, the optimum blend leading to the highest compressive strength was $67.2 \%$ FA, $18 \%$ of HPA and $14.8 \%$ of GGBFS. Thus, about $85.2 \%$ of the blend is composed of low calcium class $\mathrm{F}$ fly ash. The same aluminosilicate blend and activator are used in this study.

\subsection{Aggregate}

Sydney sand was used as fine aggregate. The coarse aggregate was $10 \mathrm{~mm}$ nominal size crushed basalt. The grading curves of both types of aggregate are presented in Fig. 2.

\subsection{Geopolymer concrete mix design and batching procedure}

The Geopolymer concrete mix is presented in Table 2. The triple aluminosilicate blend was mixed dry for about 3 min together with all aggregates prior to gradually adding the alkaline solution and then the free 
Fig. 2 Grading curves of fine and coarse aggregates

Table 2 Geopolymer concrete mix

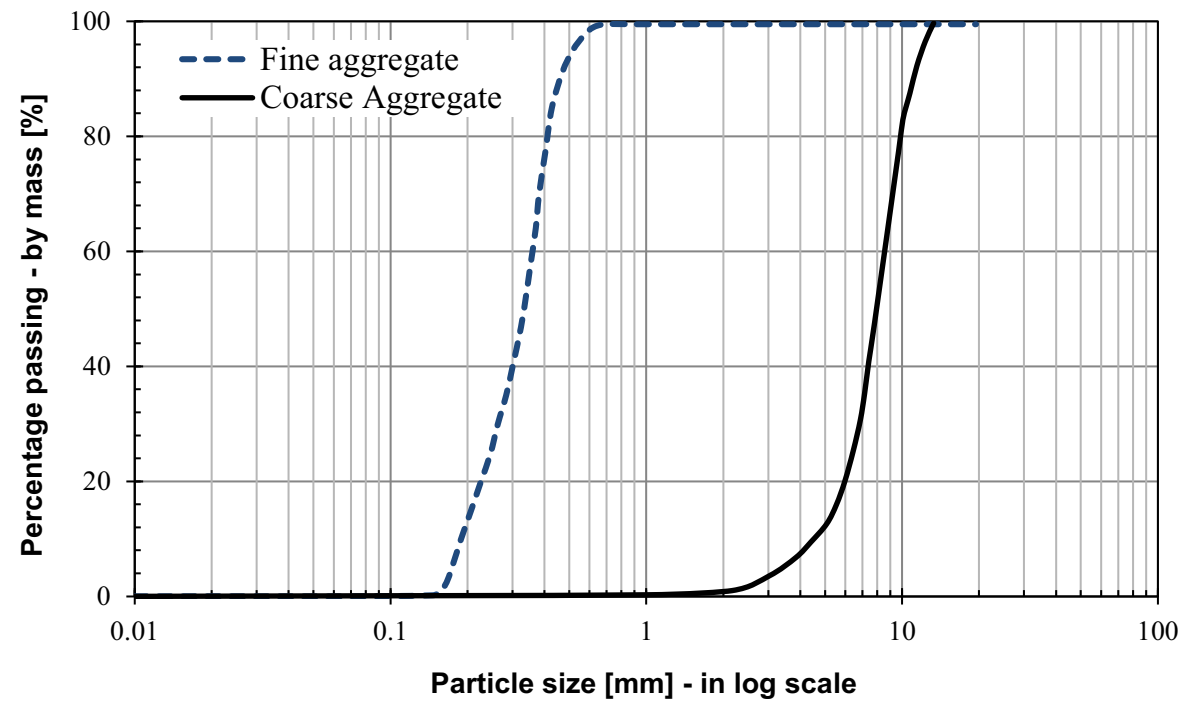

\begin{tabular}{lll}
\hline Materials & Percentage by mass $(\%)$ & $\mathrm{kg} / \mathrm{m}^{3}$ \\
\hline Coarse aggregate & 48.5 & 1144.6 \\
Fine aggregate & 30.1 & 710.4 \\
Standard fly ash (FA) & 8.2 & 193.5 \\
High performance fly ash (HPA) & 2.2 & 51.9 \\
Ground granulated blast furnace slag & 1.8 & 42.5 \\
Activator solution $\left(\mathrm{Na}_{2} \mathrm{SiO}_{3}: \mathrm{NaOH}=2.5: 1\right)$ & 6.7 & 158.1 \\
$12 \mathrm{M} \mathrm{NaOH}\left(1.9 \%=45.2 \mathrm{~kg} / \mathrm{m}^{3}\right)$ & - & - \\
$\mathrm{Na}_{2} \mathrm{SiO}_{3}\left(4.8 \%=112.9 \mathrm{~kg} / \mathrm{m}^{3}\right)$ & - & - \\
Free water & 2.5 & 59.0 \\
Fresh concrete density & - & $2360 \mathrm{~kg} / \mathrm{m}^{3}$ \\
Fresh concrete air content & - & $3.1 \%$ \\
Slump & - & $130 \mathrm{~mm}$ \\
\hline
\end{tabular}

water. The geopolymer concrete specimens used to measure the compressive and tensile strengths were compacted by using a poker vibrator just after the concrete was poured into the moulds in two phases. Pull-out specimens were compacted using a vibrating table just after being poured in the moulds also in two phases. The workability of the fresh concrete was assessed using the standard slump test. The slump obtained was $130 \mathrm{~mm}$. Air content of the fresh concrete was about $3 \%$.

\subsection{Curing procedures}

Four curing procedures were adopted for specimens used for the drying shrinkage tests:
- 1D40-curing After casting, specimens were sealed to prevent excessive loss of moisture, stored at $40{ }^{\circ} \mathrm{C}$ in an oven for 1 day. Shrinkage tests were started after $24 \mathrm{~h}$.

- 1D80-curing After casting, specimens were sealed to prevent excessive loss of moisture, stored at $80{ }^{\circ} \mathrm{C}$ in an oven for 1 day. Shrinkage tests were started after $24 \mathrm{~h}$.

- 3D40-curing After casting, specimens were sealed to prevent excessive loss of moisture, stored at $40{ }^{\circ} \mathrm{C}$ in an oven for 3 days. Shrinkage tests were started after 3 days.

- 7D80-curing After casting, specimens were sealed to prevent excessive loss of moisture, stored at $40{ }^{\circ} \mathrm{C}$ in an oven for 1 day and then cured in a 
$80{ }^{\circ} \mathrm{C}$ water bath for a further 7 days. Shrinkage tests were started after 8 days.

The two curing procedures used for creep test specimens are:

- 3D40-curing After casting, specimens were sealed to prevent excessive loss of moisture, stored at $40{ }^{\circ} \mathrm{C}$ in an oven for 3 days and then stored in a controlled room at $23{ }^{\circ} \mathrm{C}$ and $60 \%$ relative humidity. Creep tests were started after 8 days.

- 7D80-curing After casting, specimens were sealed to prevent excessive loss of moisture, stored at $40{ }^{\circ} \mathrm{C}$ in an oven for 1 day and then cured in a $80{ }^{\circ} \mathrm{C}$ water bath for a further 7 days. Creep tests were started after 8 days.

\subsection{Testing program}

The compressive strength and the instantaneous elastic modulus were measured after 28 days on standard concrete cylinders (diameter $=100 \mathrm{~mm}$, height $=200 \mathrm{~mm}$ ) in accordance with AS 1012.9 [23].

The drying shrinkage tests were performed on $75 \mathrm{~mm} \times 75 \mathrm{~mm} \times 300 \mathrm{~mm}$ prisms in accordance with AS1012.13 [24]. During the tests the specimens were kept in a controlled temperature environment. The temperature and the relative humidity were maintained at about $23{ }^{\circ} \mathrm{C}$ and $60 \%$ respectively. Drying shrinkage tests were started after $24 \mathrm{~h}$ for curing conditions 1D40-curing and 1D80-curing, after 3 days for curing condition 3D40-curing and after 8 days for curing condition 7D80-curing. Three specimens were tested for each curing condition for about 90 days. All specimens heat cured in the $80{ }^{\circ} \mathrm{C}$ water bath were saturated when starting the shrinkage tests. Regarding the specimens cured at $40{ }^{\circ} \mathrm{C}$, it is assumed that no significant water evaporation occurred as all specimens were sealed. Pan et al. [25] recently reported that the free moisture content of geopolymer is similar to that of OPC concrete which is in the order of $5-8 \%$ as can be seen from TGA when heated to about $110{ }^{\circ} \mathrm{C}$. The results presented are total shrinkage which combines the chemical and drying shrinkage. In this study we are interested in the total rather than the individual components.

The creep tests were performed on $100 \mathrm{~mm}$ diameter cylinders with $200 \mathrm{~mm}$ height in accordance with Australian Standard AS1012.16 [26]. All creep tests were started 8 days after casting and the sustained load applied was $40 \%$ of the compressive strength as determined on the day of starting the creep testing. Three specimens were tested for each curing condition for about 90 days. Both shrinkage and creep results were compared to the values calculated for an equivalent $\mathrm{OPC}$ based concrete using the Australian Standard [19].

\section{Experimental results}

\subsection{Mechanical characteristics}

Figures 3 and 4 show the increase of the average compressive strength and elastic modulus, respectively, versus the duration of the heat curing period at $80{ }^{\circ} \mathrm{C}$. All measurements were performed at 28 days after casting. For compressive strength, three tests were performed for each curing condition. The elastic modulus was measured using one specimen only. Figure 3 shows that the compressive strength of the geopolymer concrete increases greatly with the increasing duration of the $80{ }^{\circ} \mathrm{C}$ curing period. The maximum average compressive strength measured was about $58 \mathrm{MPa}$ and was obtained after 7 days of heat curing. Whereas the $80{ }^{\circ} \mathrm{C}$ curing for 1 day only led to an average compressive strength of about $36 \mathrm{MPa}$. However, the benefit on the compressive strength of increasing the duration of the $40{ }^{\circ} \mathrm{C}$ curing period is only moderate. The scatter of both the compressive and tension strength measurements is reasonably low for all tests (Table 3). Figure 4 shows

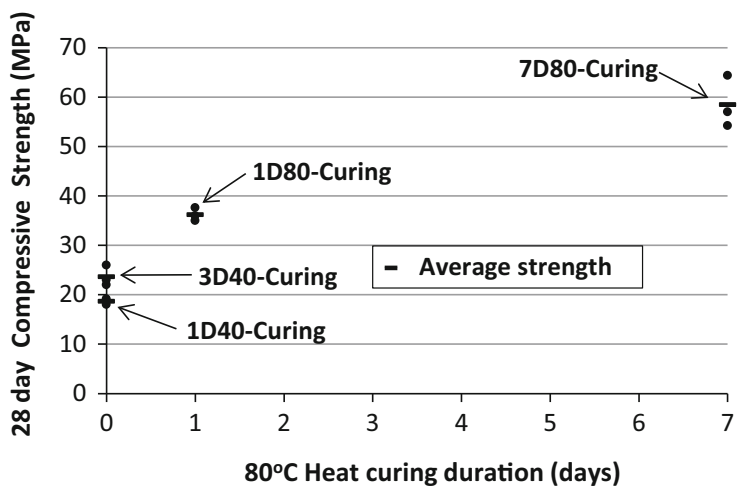

Fig. 3 Increase in 28 day compressive strength versus the duration of the heat curing period 


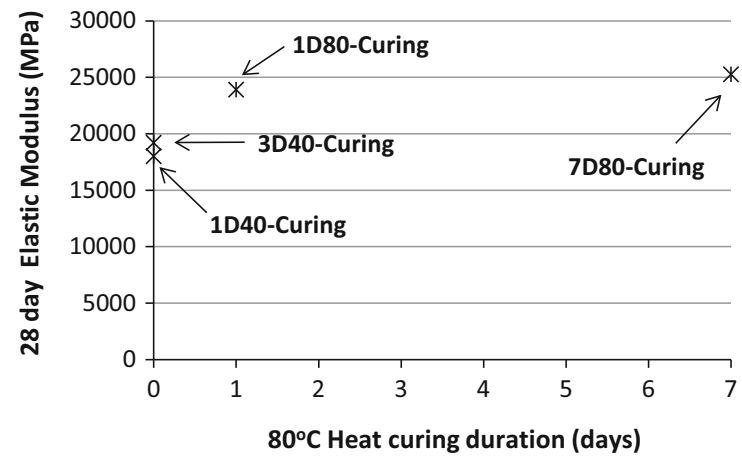

Fig. 4 Increase in 28 day elastic modulus versus the duration of the heat curing period

that the elastic modulus is close to the maximum value after 1 day in the $80{ }^{\circ} \mathrm{C}$ water. There appears to be little benefit in increasing the duration of the $40{ }^{\circ} \mathrm{C}$ curing period on the elastic modulus.

\subsection{Drying shrinkage tests}

Figure 5 compares the drying shrinkage measured on the specimens cured for 1 day at $40{ }^{\circ} \mathrm{C}$ and 1 day at $80{ }^{\circ} \mathrm{C}$. In Fig. 5, experimental results are compared to the values calculated for an equivalent OPC based concrete using Eurocode 2 (EN 1992-1-1, [27]). Only the drying shrinkage was taken into account to calculate the time-dependent shrinkage strain for all curing regimes. The shrinkage strains measured on the specimens cured for 1 day at $40{ }^{\circ} \mathrm{C}$ were about three times the value calculated for OPC concrete in accordance with Eurocode 2 (EN 1992-1-1, [27]). However, in the case of $80{ }^{\circ} \mathrm{C}$ cure for 1 day, the drying shrinkage strain was similar or less than that specified in Eurocode 2. For the specimens cured for 3 days at $40{ }^{\circ} \mathrm{C}$, the shrinkage strain was also similar to that specified in Eurocode 2, as shown in Fig. 6. Extending the duration of heat curing up to 7 days

Table 3 Average compressive strength $f_{\mathrm{c} 28}$ and elastic modulus $E_{\mathrm{c} 28}$ after 28 days versus heat curing duration

\begin{tabular}{lllll}
\hline & $1 \mathrm{D} 40$ & $3 \mathrm{D} 40$ & $1 \mathrm{D} 80$ & $7 \mathrm{D} 40$ \\
\hline$f_{\mathrm{c} 28}(\mathrm{MPa})$ & 18.7 & 23.7 & 36.2 & 58.5 \\
$\mathrm{SD}$ & 0.5 & 2.08 & 1.31 & 5.27 \\
$E_{\mathrm{c} 28}(\mathrm{GPa})$ & 18 & 19.2 & 23.9 & 25.3 \\
$\mathrm{SD}$ & $\mathrm{n} / \mathrm{a}$ & $\mathrm{n} / \mathrm{a}$ & $\mathrm{n} / \mathrm{a}$ & $\mathrm{n} / \mathrm{a}$ \\
\hline
\end{tabular}

$S D$ standard deviation

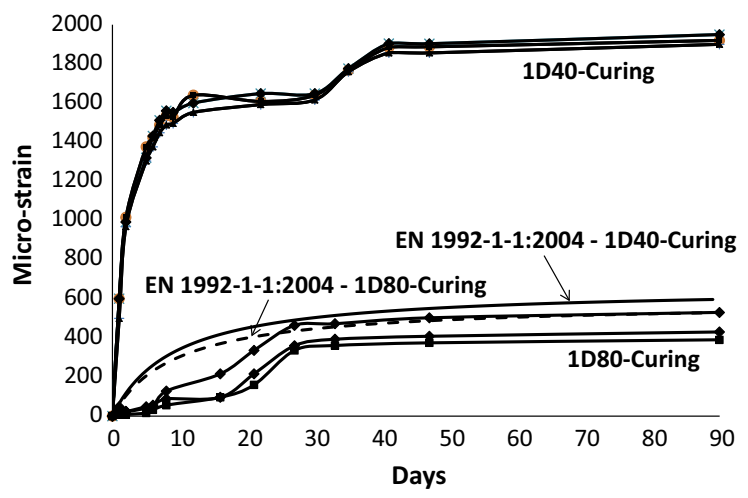

Fig. 5 Drying shrinkage measured on the specimens cured 1 day at 400 and $800{ }^{\circ} \mathrm{C}$

(Fig. 7) provides only a small benefit in terms of shrinkage reduction, even though the 28 days compressive strength of the geopolymer concrete is significantly increased (Fig. 3). It is important to note that the consistency of results over three tests is good for all curing procedures.

Figure 8 shows the average shrinkage strain obtained after 90 days for all curing conditions versus the 28 days compressive strength of the geopolymer concrete. Provided that the duration of the curing is sufficiently long and in the experimental conditions of the tests, geopolymer concrete performs well with regard to shrinkage, irrespective of the curing temperature. The effect of reduced shrinkage is related to pore size distribution as discussed in previous work by [28] where it was demonstrated that the reason for high shrinkages in alkali activated slag is related to the coarse pore size distribution. The use of fly ash in the

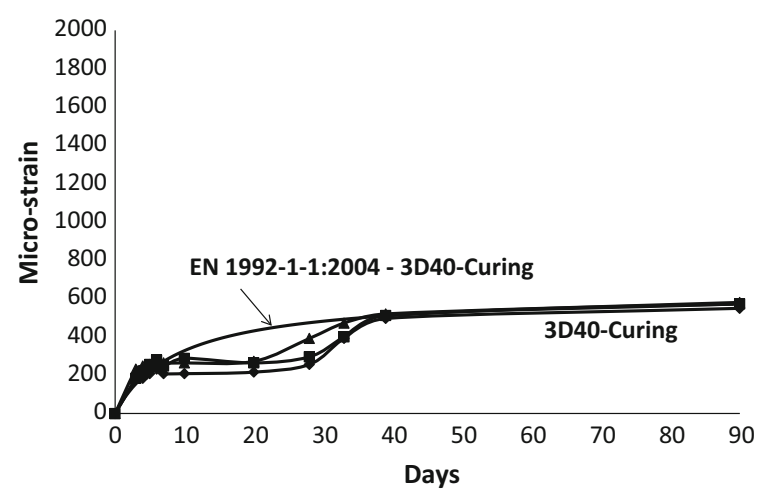

Fig. 6 Drying shrinkage measured on the specimens cured 3 days at $400{ }^{\circ} \mathrm{C}$ 


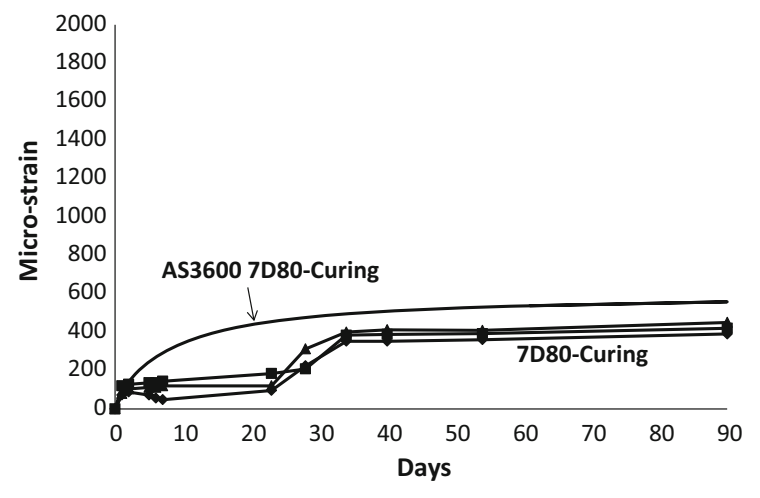

Fig. 7 Drying shrinkage measured on the specimens cured 7 days at $800{ }^{\circ} \mathrm{C}$

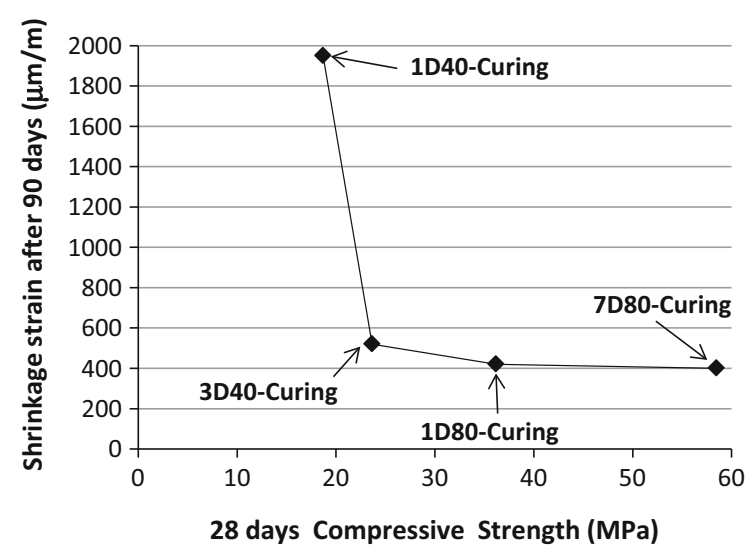

Fig. 8 Average shrinkage strain obtained after 90 days versus the 28 days compressive strength of the geopolymer concrete

system must have the opposite effect as compared to slag alone where the shrinkages are higher than comparable OPC concretes [28]. Indeed, Kovalchuk et al. investigated the microstructure development of heat cured geopolymer binder using low calcium fly ash and alkaline solution both very similar to the ones used in this study including the effect of thermal curing conditions on pore structure (total porosity and average pore diameter), down to a minimum pore diameter of $0.0067 \mu \mathrm{m}$, using a Micrometrics Autopore II 9220 porosimeter [29]. It was found that curing conditions, particularly in term of relative humidity, play an essential role in the development of a material's microstructural characteristics (such as porosity and phase composition), kinetics and degree of reaction and their respective macroscopic properties. Large pores $(10-50 \mu \mathrm{m})$ were observed on dried cured specimens lowering the compressive strength.
Dry heat curing is not recommended for low calcium fly ash systems. On the contrary, when specimens were wet cured, the resulting material developed a very dense structure which is consistent with the results reported in this paper.

At this stage of the research, it appears that heat treatment reduces the average pore size of the low calcium fly ash geopolymer concrete resulting in reduced shrinkage in spite of the resulting increase in the capillary tension. The effect is similar to that in OPC concrete where shrinkage (and creep) is generally smaller in denser, higher strength concrete.

\subsection{Creep tests}

Table 4 shows the concrete compressive strength when the creep tests were started at 8 days $\left(f_{\mathrm{c} 8}\right)$, for the two curing conditions. Three extra concrete cylinders were cast in order to measure the compressive strength after 8 days for each curing condition. The value of the sustained load applied to each specimen and the resulting measured instantaneous strains are also shown in Table 4.

Figure 9 shows the total strains measured for all specimens including the control cylinders (not loaded) which are used to assess the drying shrinkage component of the strain. Strains measured on the control cylinders are similar for both curing conditions (3D40curing and 7D80-curing) and is in accordance with drying shrinkage test results already discussed. The total strains measured on the creep specimens cured three days at $40{ }^{\circ} \mathrm{C}$ are much higher than those measured on the creep specimens cured for seven days at $80{ }^{\circ} \mathrm{C}$. The total strains measured on the specimens cured seven days at $80{ }^{\circ} \mathrm{C}$ appear to be due mostly to shrinkage.

The creep coefficient can be calculated using [30, 31]:

$\varphi\left(t, t_{0}\right)=\frac{\varepsilon_{\mathrm{cc}}\left(t, t_{0}\right)}{\varepsilon_{\mathrm{e}}}$

where $\varphi\left(t, t_{0}\right)$ is the creep coefficient, $t$ is time (in days), $t_{0}$ is the age at first loading, $\varepsilon_{\mathrm{cc}}\left(t, t_{0}\right)$ is the time dependant concrete strain due to creep and $\varepsilon_{\mathrm{e}}$ is the instantaneous elastic strain when the sustained loading is first applied. The time dependent experimental creep strain is calculated as the total strain minus the instantaneous strain and the time dependent shrinkage strain measured using the control specimens. 
Table 4 Compressive strength of the concretes after height days, sustained load applied during creep tests and concrete instantaneous strains

\begin{tabular}{lllc}
\hline & Sustained load $(\mathrm{MPa})$ & Instantaneous strain $(\mu \mathrm{m} / \mathrm{m})$ & $f_{\mathrm{c} 8}(\mathrm{MPa})$ \\
\hline 3D40-curing specimen 1 & 10 & 858 & 21.5 \\
3D40-curing specimen 2 & & 918 & \\
3D40-curing specimen 3 & & 966 & \\
7D80-curing specimen 1 & 20 & 891 & 54.3 \\
7D80-curing specimen 2 & & 929 & \\
7D80-curing specimen 3 & 912 & \\
\hline
\end{tabular}

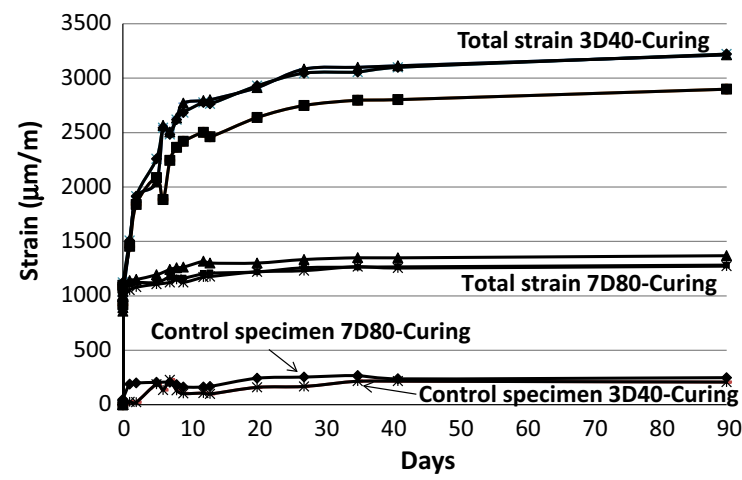

Fig. 9 Total strains measured for all specimens including the control cylinders (not loaded) used to assess the drying shrinkage strain only

The creep coefficient as determined from Eq. 1 for the 3D40-curing and 7D80-curing tests are presented in Figs. 10 and 11, respectively and compared to Eurocode 2 (EN 1992-1-1, [27]). At early age, the creep coefficient is similar to that calculated using Eurocode 2 for specimens cured for 3 days at $40{ }^{\circ} \mathrm{C}$. Beyond, 50 days, the creep coefficient appears to be less than that calculated using Eurocode 2. This is consistent with results in the literature [17, 20] showing that the addition of a minor quantity of GGBFS does not significantly affect creep (or shrinkage) of low calcium fly ash geopolymer concrete. After 7 days at $80{ }^{\circ} \mathrm{C}$, the subsequent creep is very small as the creep coefficient is only about 0.2 . As in the case of the shrinkage tests, the consistency of results over three tests is good for all curing procedures.

It is generally accepted that creep in OPC originates in the hardened cement paste that consists of a hydrated cement gel containing numerous capillary pores. The hydrated cement gel is made up of colloidal sheets of calcium silicate hydrates separated by spaces containing absorbed water. Creep in OPC concrete is thought to be caused by several different and complex

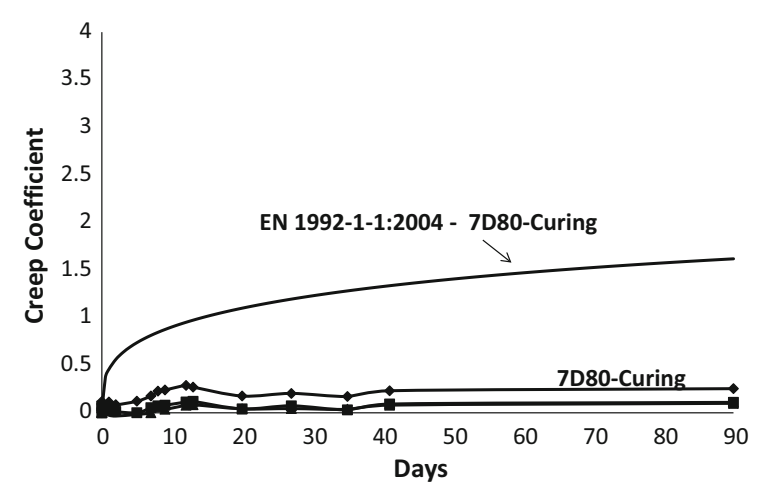

Fig. 10 Creep coefficient obtained for curing condition 8D80curing

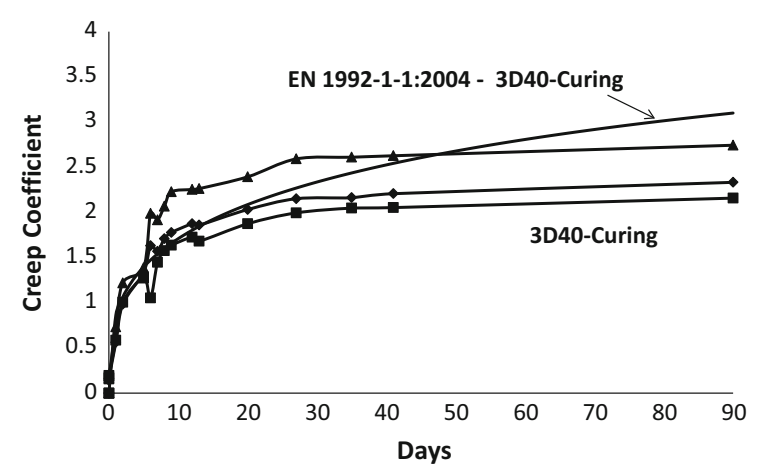

Fig. 11 Creep coefficient obtained for curing condition 3D40curing

mechanisms, including sliding of the colloidal sheets in the gel between the layers of absorbed water, expulsion and decomposition of the interlayer water within the hydrated cement gel, deformation of the aggregate and the hydrated cement gel as viscous flow and local fracture involving the breakdown (and formation) of physical bonds. The proportion of creep associated with each of these mechanisms is not yet understood despite extensive research over the last 
eighty years. Recent research relates the creep response of OPC to the packaging density distributions of calcium-silicate-hydrates [32]. The mechanisms of creep in fly ash geopolymer concrete are still to be determined and are likely to be different from those in OPC concrete.

Further research is required in order to investigate in detail the mechanisms such as change in surface energy or loss of disjoining pressure $[33,34]$ that could affect both creep and shrinkage and that could be responsible for the observed geopolymer concrete behaviour.

\section{Conclusions}

Curing at low temperature such as $40{ }^{\circ} \mathrm{C}$ requires a minimum of 3 days in order for the creep and shrinkage characteristics of the geopolymer concrete examined in this study to meet, or be lower than the nominated values in Eurocode 2 that were determined for OPC concretes. When the shrinkage tests were started after 1 day only, shrinkage strains were about three times those calculated using Eurocode 2. One day of curing at $80{ }^{\circ} \mathrm{C}$ is enough to lower the shrinkage strain to be similar to the values specified in Eurocode 2 for OPC concretes. Extending the duration of the heat curing up to 7 days provides only a modest benefit in terms of shrinkage reduction even though the 28 days compressive strength of the geopolymer concrete is significantly increased.

As reported in the literature, heat-cured fly ashbased geopolymer concrete undergoes low creep. The creep coefficient was similar or less than the values specified in Eurocode 2 for specimens cured for 3 days at $40{ }^{\circ} \mathrm{C}$. After 7 days at $80{ }^{\circ} \mathrm{C}$, creep strains were very small. It is noted that although concrete shrinkage is invariably detrimental in concrete structures, often leading to excessive cracking and deformation, the same is not necessarily true with regard to creep. The very low creep characteristics in excessively heatcured fly ash-based geopolymer concrete may be problematic in some situations and may limit its application. Gilbert and Ranzi [31] point out that creep reduces undesirable stresses in concrete caused by unintentionally imposed deformations such as support settlements, shrinkage, thermal gradients and so on. Creep relieves concrete stress concentrations and imparts deformability to concrete [35]. In fact, the success of concrete as a structural material is due, in no small way, to its ability to creep.

Acknowledgments This research is funded by the CRC for Low Carbon Living Ltd supported by the Cooperative Research Centres program, an Australian Government initiative. The experimental work was carried in the Structures Laboratory of the School of Civil and Environmental Engineering at the University of New South Wales. The assistance of the laboratory staff is also acknowledged.

\section{References}

1. Malhotra VM (2002) High-performance high-volume fly ash concrete. Concr Int 24:30-34

2. Struble J, Godfrey J (2004) How sustainable is concrete? In: International workshop on sustainable development and concrete technology, Beijing, May 20-21, pp 201-211

3. Gartner E (2004) Industrially interesting approaches to "low- $\mathrm{CO}_{2}$ " cements. Cem Concr Res 34:1489-1498

4. Josa A, Aguado A, Heino A, Byars E, Cardim A (2004) Comparative analysis of available life cycle inventories of cement in the EU. Cem Concr Res 34:1313-1320

5. CIF (2011) Cement industry federation response to the clean energy bill 2011 and related legislation. Report. Cement Industry Federation

6. Duxson P, Fernández-Jiménez A, Provis JL, Lukey GC, Palomo A, van Deventer JSJ (2007) Geopolymer technology: the current state of the art. J Mater Sci 42(9): 2917-2933

7. Ng TS, Voo YL, Foster SJ (2012) Sustainability with ultrahigh-performance and geopolymer concrete construction. In: Fardis MN (ed) Innovative materials and techniques in concrete construction: ACES workshop. Springer, Dordrecht, pp 81-100

8. Ng TS, Foster SJ (2012) Development of a mix design methodology for high-performance geopolymer mortars. Struct Concr 14(2):148-156

9. Xu H, Provis JL, van Deventer JSJ, Krivenko PV (2008) Characterization of Aged slag concretes. ACI Mater J 105(2):131-139

10. Davidovits J (1991) Geopolymers: inorganic polymeric new materials. J Therm Anal 37:1633-1656

11. Aly T, Sanjayan JG (2010) Effect of pore-size distribution on shrinkage of concretes. J Mater Civ Eng 22(5):525-532

12. Lloyd NA, Rangan BV (2010) Geopolymer concrete with fly ash. In: 2nd international conference on sustainable construction materials and technologies, pp 1493-1504

13. Provis JL, van Deventer JSJ (2009) Geopolymers: structures, processing, properties, and industrial applications. Woodhead Publishing Limited, Cambridge

14. Sagoe-Crentsil K (2009) Role of oxide ratios on engineering performance of fly-ash geopolymer binder systems. Ceram Eng Sci Proc 29(10):175-184

15. Fernandez-Jimenez AM, Palomo A, Lopez-Hombrados C (2006) Engineering properties of alkali-activated fly ash concrete. ACI Mater J 103(2):106-112 
16. Sofi M, van Deventer JSJ, Mendis PA (2007) Engineering properties of inorganic polymer concretes (IPCs). Cem Concr Res 37:251-257

17. Wallah SE (2010) Creep behaviour of fly ash based geopolymer concrete. Civ Eng Dimens 12(2):73-78

18. Wallah SE, Rangan BV (2006) Low calcium fly ash based geopolymer concrete: long term properties. Faculty of Engineering, Curtain University of Technology, Perth, Australia

19. AS3600 (2009). Concrete structures. Standards-Australia

20. Sagoe-Crentsil K, Taylor A, Brown T (2013) Drying shrinkage and creep performance of geopolymer concrete. J Sustain Cem-Based Mater 2(1):35-42

21. ASTM C157 (2009) Standard test method for length change of hardened hydraulic-cement mortar and concrete

22. Palomo A, Grutzeck MW, Blanco MT (1999) Alkali-activated fly ashes A cement for the future. Cem Concr Res 29:1323-1329

23. AS 1012.9 (1999). Methods of testing concrete-determination of the compressive strength of concrete. StandardsAustralia

24. AS1012.13 (1992) Methods of testing concrete-determination of drying shrinkage of concrete for samples prepared in the field or in the laboratory. Standards-Australia

25. Pan Z, Sanjayan JG, Collins F (2014) Effect of transient creep on compressive strength of geopolymer concrete for elevated temperature exposure. Cem Concr Res 56:182-189

26. AS1012.16 (1996) Methods of testing concrete-determination of creep of concrete cylinders in compression. Standards-Australia
27. EN 1992-1-1 (2004) Eurocode 2: design of concrete structures-part 1-1: general rules and rules for buildings

28. Collins F, Sanjayan JG (2000) Effect of pore size distribution on drying shrinkage of alkali activated slag concrete. Cem Concr Res 30(9):1401-1406

29. Kovalchuk G, Fernandez-Jimenez A, Palomo A (2007) Alkali-activated fly ash: effect of thermal curing conditions on mechanical and microstructural development-part II. Fuel 86:315-322

30. Gilbert RI (2002) Creep and shrinkage models for high strength concrete-proposal for inclusion in AS3600. Austr J Struct Eng 4:95-106

31. Gilbert RI, Ranzi G (2011) Time-dependent behaviour of concrete structures. Spon, London, p 426

32. Vandamme M, Ulm F-J (2009) Nanogranular origin of concrete creep. Proc Natl Acad Sci 106(26):10552-10557

33. Bažant ZP, Hauggaard AB, Baweja S, Ulm F (1997) Microprestress-solidification theory for concrete creep. I: aging and drying effects. J Eng Mech 123(11):1188-1194

34. Ferraris CF, Wittmann FH (1987) Shrinkage mechanisms of hardened cement paste. Cem Concr Res 17(3):453-464

35. Castel A, Gilbert RI, Ranzi G (2014) Instantaneous stiffness of cracked reinforced concrete including steel-concrete interface damage and long-term effects. ASCE J Struct Eng 140(6):04014021 